\title{
Verbal context as a retrieval cue in long-term memory for words'
}

MIC!IAEL J. A. HOWE

\author{
DEPARTMENT OF EDUCATION, TUFTS UNIVERSITY
}

Ss were required to complete sentences by filling word blanks in short prose passages which were designed to provide minimal constraints upon the nature of the items to be supplied. Two days later the $S$ s attempted to reproduce the words they had produced. Provision of the original passages on this occasion increased the level of recall. Since the results showed that little constraint was provided by the passages, it was suggested that the latter improved performance by functioning as retrieval cues.

There has lately been an increasing awareness of the important role of retrieval processes in memory. Tulving \& Pearlstone (1966) have drawn attention to the fact that failure to recall verbal items may often be due to a fallure to locate material which is stored intact, and not to items becoming unavailable because the memory system is unable to store them. Stored items differ in accessibility, and the ease with which they can be retrieved may depend on both the efficiency with which they were coded when they were initially stored, and the availability of appropriate retrieval cues at the time of recall. Phenomena such as the "tip of the tongue" (Brown \& McNeill, 1966) and "feeling-of-knowing" (Hart, 1965) experiences indicate that a person may be aware that certain material is retained in his memory and yet be unable to reproduce it. There is evidence to suggest that the provision of appropriate cues (Tulving \& Pearlstone, 1966; Jung, 1967) may facilitate the locating of stored items, and thus improve accuracy of recall.

A familiar situation in which recall cues seem to lead to an increase in correct reproduction exists when someone is "prompted" to recall a line of verse or prose by being told the first few words. This procedure may, of course, facilitate reproduction not only by providing a recall cue; an effect might be to give contextual constraint which would raise the probability of an intelligent guess being correct. However, if one can devise a situation in which the possibility of such an effect is absent, it would be interesting to determine whether providing retrieval cues in the form of verbal context affects the level of correct recall.

\section{Method}

There were $151 \mathrm{Ss}$, who were students enrolled in a course in introductory psychology. They were tested together. Each S received written instructions, together with a sheet of paper on which were typed five-word passages which could be made to form sentences by replacing a blank item between two of the words by a sixth word. The passages, and the positions of the blank items, were chosen so as to place as little constraint as possible, except as regards grammatical form, upon the nature of the word to be provided. A typical passage was "There is a over there." $\mathrm{S}$ was given six passages, and his instructions were to write in each blank a word which would complete the sentence, using six different words.

Two days later Ss attempted to recall the words they had provided. For this session the Ss were divided haphazardly into two groups, which (due to an administrative oversight) numbered 54 and $97 \mathrm{Ss}$, respectively. Again, all Ss were tested together. One group (Group 1) received contextual retrieval cues in the form of the passages they had originally been given on the previous session. Group 2 received no such cues.

\section{Results}

The mean numbers of words correctly recalled were 4.93 for Group 1 and 4.09 for Group 2. The difference between these means is significant beyond the .001 level $(t=3.11)$. Thus, those Ss who were provided with retrieval cues in the form of the original word contexts performed significantly better in the recall task than the other Ss.

The extent to which Ss conformed in their choice of words to fill the blanks in the first session gives an indication of the degree of constraint exerted by the prose passages. In fact, the $151 \mathrm{Sg}$ supplied between 71 and 94 different words for each passage $(M=84)$, so it can be inferred that the passages did not exert sufficient constraint to have an appreciable effect on performance in the recall session.

\section{Discussion}

The results of this very simple experiment demonstrate that giving retrieval cues in the form of verbal context improves recall scores; the results thus support the position that failure to reproduce items may often be due to what Tulving \& Pearlstone (1966) term "inaccessibility" of material rather than failure to retain it. Retrieval is clearly an important stage in memory, and it is conceivable that part of the interfering effect of recalling items upon the retention of other stored material (Howe, 1965) may be functionally related to limitations in retrieval processes. However, it is important to draw a distinction between retrieval and recall, since recalling stored items necessitates functions in addition to retrieval. 
Considering that two days elapsed between the experimental sessions, level of recall was noticeably high, in both Groups 1 and 2. The fact that the items to be recalled had been produced by the Ss themselves probably contributed to this. The Ss were not entirely naive to psychological experiments, and although they were not told on the first session that they would subsequently have a retention test, informal questioning revealed that some Ss suspected that this might be the case.

\section{References}

BROWN, R., \& McNEILL, D. The "tip of the tongue" phenomenon. J. verbal Learn. verbal Behav., 1966, 5, 315-337.
HART, J. T. Memory and the feeling-of-knowing experience. J. educ. Psychol., 1965, 56, 208-216.

HOWE, M. J. A. Intra-list differences in short-term memory. Quart. J. exp. Psychol., 1965, 17, 338-342.

JUNG, J. Cued versus non-cued incidental recall of successive word associations. Canad. J. Psychol., 1967, 21, 196-203.

TULVING, E., \& PEARLSTONE, Z. Availability versus accessibility of information in memory for words. J. verbal Learn. verbal Behav., $1966,5,381-391$.

Note

1. The author is grateful to Dr. P. H. R. James, who made available the subjects for this study, and to Barbara Candow, who assisted with the collection and processing of the data. The experimental work was carried out at Dalhousie University, Halifax, Canada, where the author held a Post-Doctoral Fellowship. 